\title{
Post-Traumatic Stress Disorder and Associated Factors Among Internally Displaced People in South Ethiopia: A Cross-Sectional Study
}

This article was published in the following Dove Press journal: Neuropsychiatric Disease and Treatment

\author{
Derebe Madoro' \\ Habtamu Kerebih (iD ${ }^{2}$ \\ Yodit Habtamu (D ${ }^{3}$ \\ Meseret G/tsadik ${ }^{3}$ \\ Hirbaye Mokona (1) \\ Alemayehu Molla (iD) \\ Tirusew Wondie' \\ Kalkidan Yohannes' \\ 'Department of Psychiatry, College of \\ Medicine and Health Sciences, Dilla \\ University, Dilla, Ethiopia; ${ }^{2}$ Department \\ of Psychiatry, School of Medicine, College \\ of Medicine and Health Sciences, \\ University of Gondar, Gonidar, Ethiopia; \\ ${ }^{3}$ Research and Training Department, \\ Amanuel Mental Specialized Hospital, \\ Addis Ababa, Ethiopia
}

Correspondence: Derebe Madoro Department of Psychiatry, College of Medicine and Health Sciences, Dilla University, PO. Box 419, Dilla, Ethiopia Email derebemd@gmail.com
Background: Displaced people experience different traumatic events. This can have serious and long-lasting consequences in terms of physical and mental health outcome. Posttraumatic stress disorder (PTSD) is the most frequent mental disorder following traumatic exposure. In 2018 Ethiopia saw the highest number of internal displacement, despite this, less attention has been given to mental health among internally displaced people in the country. This study aims to determine the estimated prevalence and associated factors of PTSD among internally displaced people in the Gede'o zone, south Ethiopia.

Participants and Methods: A community-based cross-sectional study was conducted between 1 and 30, May 2019 among 636 participants, who were selected using a simple random sampling technique. PTSD was measured by the Post-Traumatic Stress Disorder Checklist for DSM-5 (PCL-5). The association between outcome and independent variables was identified by bi-variable and multivariate logistic regression. Finally, variables with P-value less than 0.05 were considered statistically significant at $95 \% \mathrm{CI}$.

Results: A total of 625 participants were interviewed with a response rate of $98.3 \%$. The estimated prevalence of PTSD was $58.4 \%$ with $95 \%$ CI 55 to 61.9. In the multivariate logistic regression, being female ( $\mathrm{AOR}=2.4,95 \% \mathrm{CI} 1.6$ to 3.4 ), depression ( $\mathrm{AOR}=2.6,95 \%$ CI 1.2 to 3.9), displaced more than once (AOR=3.7, 95\% CI 2.4 to 5.8), destruction of personal property (AOR=1.6, 95\% CI 1.04 to 2.44), witness the murder of family (AOR=2, $95 \%$ CI $1.2,3.9)$, and cumulative trauma $(\mathrm{AOR}=4,95 \% \mathrm{CI} 1.7$ to 9.6$)$ were significantly associated factors.

Conclusion: In the current study, the estimated prevalence of PTSD was high. Ministry of health should plan routine screening and management of PTSD, depression and linking with available mental health service is recommended.

Keywords: post-traumatic stress disorder; PTSD, internal, displacement, Ethiopia

\section{Introduction}

Internally Displaced Persons (IDP) are groups who have been forced to leave their homes, but remain within the borders of their own country. ${ }^{1}$ According to a new report from a 2018 Internal Displacement Monitoring Center (IDMC) and Norwegian refugee council (NRC), globally a total of 30.6 million people were internally displaced due to conflict and disaster. ${ }^{2}$ Most of them live in low-income countries which are sometimes affected by internal conflict and violence. ${ }^{3}$ In 2016 , the total number of displaced people due to conflict in Africa was almost 12.6 million. $^{4}$ 
Ethiopia saw the highest number of internal displacements in the first half of 2018. According to the IDMC report, 1.4 million people experienced internal displacement. $^{2}$ In Gede'o zone (Southern Nation Nationality Region) and west Guji (Oromo region) more than a million people were displaced due to intercommunal conflict. $^{2}$ Generally people with displacement were exposed to different kinds of trauma, violence, and injuries, making them more vulnerable for psychological disorders, particularly post-traumatic stress disorder (PTSD). ${ }^{5}$

PTSD is one of the psychological disorders which can be experienced following exposure to a traumatic or stressful event. it is characterized by symptoms of intrusion, avoidance, changes in mood and cognition, and hyperarousal, all of which can last for more than a month after the traumatic event. ${ }^{6-8}$ PTSD can occur due to witnessing and being exposed to terrible events such as murder, threats, kidnap, loss of relatives or friends, loss of house, and starvation. ${ }^{5}$

Several systematic reviews indicated that IDP who stay within their own country experience worse mental health outcomes than refugees. ${ }^{9,10}$ PTSD symptoms have been described as one of the most prevalent mental health conditions in IDP. ${ }^{11}$ In post-conflict and conflict-ridden societies, the prevalence rates in the general population can be much higher. ${ }^{12}$

In a study looking at the lifetime prevalence of PTSD, mood, and anxiety disorders in four post-conflict societies the researchers reported a PTSD prevalence ranging from $15.8 \%$ to $37.4 \%{ }^{13}$ Statistical estimates showed that PTSD is between $1 \%$ and $5 \%$ in a range of general population studies $^{14,15}$ and between 3\% and 58\% for high-risk groups such as displaced people. ${ }^{16,17}$ The global economic burden of stress-related mental illness is expected to rise in the coming decade. The World Health Organization's (WHO) global disease of burden survey estimates that mental illness, including stress-related disorders, will be the second leading cause of disability by the year $2020 .^{18}$ A systematic review conducted in 40 countries showed that the prevalence of PTSD among IDP was $30.6 \%$. Another systematic review undertaken revealed that PTSD among IDP ranges 3\% to $88 \%{ }^{19,20}$

Studies undertaken in Africa show that PTSD can still be a public health concern several years after the civil conflict. $^{21-23}$ In East Africa, like Uganda, the prevalence of PTSD ranges from $11.8 \%$ to $54 \% .^{24-29}$ The prevalence of PTSD among IDP ranges from $3.6 \%$ to $88 \%$ in different studies from different countries. ${ }^{30-35}$

Mental illness, and specifically PTSD, is documented as a key public health issue of a conflict-affected population; war and armed conflicts contribute to poverty, lack of employment, community violence, insecure living circumstances, and changes in the social dynamic. This makes PTSD highly associated with a lower quality of life, even after the end of the actual hostilities in a post-disaster setting. ${ }^{34,35}$ Factors that contribute to the development of PTSD have been classified into four groups: pre-existing factors like family history of mental illness and substance abuse history, the traumatic event itself, the level of exposure, and post-trauma factors such as social support. ${ }^{36-38}$

Most psychiatric findings are limited to other African countries, such as Nigeria or Uganda, where studies have shown that exposure to psycho-trauma among IDP leads to PTSD. ${ }^{32,39,40}$ Even though the prevalence of PTSD is high among IDP, as far as we know there is no specific published study on Ethiopia.

\section{Materials and Methods Study Design, Period and Setting}

A community-based cross-sectional study was conducted from 1 to 30 April 2019. The study was conducted in Gede'o zone, Southern Nations, Nationalities, and Peoples' Region (SNNPR) of Ethiopia. The assessment site was affected by internal displacement due to intercommunal violence along the borders of the Gede'o (SNNPR) and West Guji (Oromo region) zones, which led to large-scale displacement, loss of life, and damage to property. IDP lived in temporary camps at different sites.

\section{Study Participants and Sampling Procedure}

A simple random sampling technique was used to select 636 participants. Since IDP were included from three sites (Gedeb, Yirgacheffe, and Dilla), to assure representativeness of the sample, proportional allocation was done to the number of IDPs located in each site. The lists of persons were obtained from the leaders of each site, and participants were selected using a computer-generated random method. For an eligible participant who was not found at their assigned camp, the interviewers revisited the area at another time during the data collection period. The study included all displaced people residing in the Gede'o zone 
who were aged 15 years and above and were living in collective sites. About $88 \%$ were under 45 years of age and those who were severely ill or had difficultycommunicating were excluded from the study.

\section{Sample Size Determination}

We determined the sample size by using a single population proportion formula with the assumptions of $36 \%$ prevalence of PTSD from studies conducted in South Sudan $;{ }^{41} 0.36=\mathrm{P}, 1.96=\mathrm{Z}$ (standard normal distribution), $95 \% \mathrm{CI}$, margin of error 0.04 and after using $10 \%$ nonresponse rate total sample size was 636 .

\section{Data Collection Instruments}

Data was collected using interviewer administered structured and pretested questionnaires. It was collected by six BSc nurses and regularly supervised by two psychiatry professionals. The questionnaire was designed in English and translated to Amharic and back to English to maintain consistency. Data collectors were trained on how to interview participants and explain unclear questions and the purpose of the study.

PTSD was measured using the Post-Traumatic Stress Disorder Checklist for DSM-5 (PCL-5). The PCL-5 is standardized instrument and is a self-report rating scale for assessing the 20 DSM-5 symptoms of PTSD. ${ }^{43}$ A total score was computed by adding the 20 items, so that possible scores range from 0 to 80 with a 5 -point Likert scale $(0=$ Not at all, $1=$ A little bit, $2=$ moderately, $3=$ Quite a bit, $4=$ extremely) with a cut off point of $\geq 33 .{ }^{43}$ Validity and reliability of the PCL-5 have been tested and proven on displaced people and refugees in a number of countries, for example, in Iraq (Cronbach's alpha $=0.85){ }^{44}$ and Zimbabwe (Cronbach's alpha $=0.92) .{ }^{45}$

Depression was measured using the Hopkins' Symptom Checklist-25 (HSCL-25) in which scores for symptom criteria of depression was measured using the 15 depression items from the HSCL-25. ${ }^{46}$ This also had a 4-point severity scale $1=$ Not at all, $2=$ A little, $3=$ Quite a bit, and $4=$ Extremely. Mean depression scores $\geq 1.75$ were considered significant for meeting symptom criteria of depression based upon the instrument standards. ${ }^{46}$ The reliability and validity of the HSCL-25 have been tested and proven for use with displaced persons in a number of countries. $^{47}$

Social support was measured according to the Oslo-3 social support scale which ranges from 3 to 14, those respondents who score between 3 and 8 are considered to have poor social support, a score of 9-11 is considered as having moderate social support, and a score of $12-14$ is considered as having strong social support. ${ }^{48}$ Other stressful life events are measured by the presence of one or more item from the list of stressful life event questionnaires over an entire life. ${ }^{49}$ Socio-demographic factors, substance use history, clinical factors, trauma- and displacement-related factors were used on "yes/no" response questionnaires and were operationalized according to different literature.

\section{Statistical Analysis}

Data was entered into the computer using EPI Data version 4.2 and exported to statistical package for social science (SPSS) version 24 for analysis. Descriptive data was summarized using tables. Binary logistic regression was used to identify factors associated with outcome variable. Variables with a $\mathrm{P}$ value of less than 0.2 in bivariate regression were included for multivariate logistic regression. Finally, P-value $\leq 0.05$ in multivariate logistic regression was considered as statistically significant and the strength of associations was determined using adjusted odds ratio (AOR) at $95 \% \mathrm{CI}$.

\section{Ethical Approval and Consent to Participation}

All procedures undertaken during data collection were in accordance with the ethical review board of the University of Gondar, Amanuel mental specialized hospital, with the ethical approval number AM/146/4/106 and the Helsinki Declaration. The study was approved by the ethical review board of the University of Gondar and Amanuel mental specialized hospital. The participants were informed about the aim of the study and no identification or names were recorded so as to maintain confidentiality. The study participants were informed of their right to refuse or stop participating at any time during the interview. Finally, data were collected after obtaining written informed consent from the participants. For participants who were found to have PTSD during the study, further assessment of their condition was carried out at a nearby psychiatric clinic.

\section{Results}

\section{Socio-Demographic Characteristics of the Respondents}

A total of 625 participants were included in the study with a response rate of $98.3 \%$. The mean age $( \pm \mathrm{SD})$ of the respondents was $32.98( \pm 11.22)$ years, with age ranging 
from 18 to 79 years. Among the respondents 194 (31.04\%) were in the age range of 25-34 years, 328 (52.48\%) were male, 345 (55.2\%) were married and 292 (46.7\%) were attended primary school. Regarding occupation, about 252 $(40.3 \%)$ were farmers, while $176 \quad(28.2 \%)$ were merchants (Table 1).

\section{Clinical, Psychosocial, Substance and Displacement-Related Factors of Respondents}

With regard to the the clinical characteristics of the respondents, more than half of the participants $(333 ; 53.3 \%)$ had depression, $31(4.96 \%)$ had a family history of mental illness, $36(5.76 \%)$ were ever treated for mental illness and 168 (26.9\%) had co-morbid medical illness. Of the total study participants, more than half of the participants $(364 ; 58.2 \%)$

Table I Distribution of Socio-Demographic Factors Among Internally Displaced Peoples in Southern Ethiopia, 2019 ( $n=625)$

\begin{tabular}{|l|l|l|}
\hline Variables & Frequency & Percent (\%) \\
\hline Age & & \\
I5-25 & 176 & 28.16 \\
$26-35$ & 194 & 31.04 \\
$36-45$ & 178 & 28.48 \\
$46-55$ & 49 & 7.84 \\
$>55$ & 28 & 4.48 \\
\hline Sex & & \\
Male & 328 & 52.5 \\
Female & 297 & 47.5 \\
\hline Marital status & & \\
Married & 345 & 55.2 \\
Single & 152 & 24.3 \\
Divorced & 39 & 6.24 \\
Separated & 28 & 4.48 \\
Widow/er & 61 & 9.76 \\
\hline Education status & & \\
No formal education & 138 & 22.1 \\
Primary & 296 & 47.4 \\
Secondary & 116 & 18.56 \\
Preparatory & 61 & 9.76 \\
College and above & 14 & 2.24 \\
\hline Occupation & & \\
Farmer & 178 & 18.2 \\
Merchant & 55 & 4.2 \\
Employed (gov't and private) & 114 & \\
Student & 26 & \\
Others* & & \\
\hline
\end{tabular}

Note: Others*, House wife, daily laborer and jobless. had never been previously displaced and 261 (41.76\%) had been displaced more than once. About three-quarters of the respondents (480; 76.8\%) spent between 9 and 12 months in displacement areas. Regarding the psychosocial characteristics of respondents, more than half of the participants with PTSD (336; 53.76\%) had poor social support and most (550; $88 \%$ ) of the respondents had experienced other stressful life events. With respect to substance use, more than one-third of respondents $(194 ; 31.04 \%)$ were lifetime alcohol users, and $133(21.28 \%)$ were current alcohol users (Table 2).

\section{Trauma-Related Factors}

Regarding individual trauma type, the most frequent type of trauma experienced by the IDP was the destruction of personal property $(422 ; 67.52 \%)$ and a lack of food and water $(382 ; 61.12 \%)$. More than half $(348 ; 55.68 \%)$ had experienced or witnessed the murder of family or friends. With regard to cumulative trauma events, nearly half ( 308 ; $49.28 \%$ ) of respondents had experienced between 0 and 3 traumatic events and around half (51.8\%) of respondents had experienced $\geq 4$ of the 16 traumatic events covered by questionnaire. Generally males reported 328 (52.48\%) cumulative trauma events and female reported 297 (47.52\%). In addition, 157 (25.12\%) of the participants had experienced physical abuse in childhood (Table 3).

\section{Prevalence of Post-Traumatic Stress Disorder Among Internally Displaced People}

In this study, the estimated prevalence of PTSD was $58.4 \%$ with a $95 \%$ CI of $55 \%-61.9 \%$. The estimated prevalence rate was higher among females $(60.8 \%)$ compared to males (39.2\%).

\section{Independent Variables Associated with Post-Traumatic Stress Disorder}

Supplementary Table1 shows that variables with a P-value of less than 0.2 in bivariate regression were included for multivariable logistic regression. In the multivariate logistic regression being female, those displaced more than once, depression, witnessing the murder of a family member/friend, destruction of personal property, and cumulative trauma were statistically significant with PTSD at p-value $<0.05$.

Females were 2.35 times more likely to develop PTSD than males (AOR $=2.35,95 \%$ CI 1.61 to 3.44 ). Those who had experienced the destruction of personal property were 1.58 times more likely to develop PTSD than those who 
Table 2 Description of Clinical-, Psychosocial-, Substance- and Displacement-Related Factors of Respondents Among Internally Displaced People in Southern Ethiopia, 2019 ( $n=625)$

\begin{tabular}{|c|c|c|}
\hline Variables & Frequency & Percent (\%) \\
\hline \multicolumn{3}{|l|}{ Ever treated for mental illness } \\
\hline Yes & 29 & 4.64 \\
\hline No & 596 & 95.36 \\
\hline \multicolumn{3}{|l|}{ Family member treated for mental illness } \\
\hline Yes & 36 & 5.76 \\
\hline No & 589 & 94.24 \\
\hline \multicolumn{3}{|l|}{ Depression } \\
\hline Yes & 333 & 53.28 \\
\hline No & 292 & 46.72 \\
\hline \multicolumn{3}{|l|}{ Co-morbid medical or surgical illness } \\
\hline Yes & 168 & 26.88 \\
\hline No & 457 & 73.12 \\
\hline \multicolumn{3}{|l|}{ Prior displacement characteristics } \\
\hline Never displaced & 364 & 58.24 \\
\hline Displaced as IDPs & 253 & 40.48 \\
\hline Displaced as refugee & 6 & 0.96 \\
\hline Displaced & 2 & 0.32 \\
\hline \multicolumn{3}{|l|}{ Duration since displacement } \\
\hline $9-12$ month & 480 & 76.8 \\
\hline$>12$ month & 145 & 23.2 \\
\hline \multicolumn{3}{|l|}{ Frequency of displacement } \\
\hline I time & 364 & 58.24 \\
\hline$>$ I time & 261 & 41.76 \\
\hline \multicolumn{3}{|l|}{ Social support } \\
\hline Poor & 336 & 53.8 \\
\hline Moderate & 186 & 29.8 \\
\hline Strong & 103 & 16.5 \\
\hline \multicolumn{3}{|l|}{ Life time use of alcohol } \\
\hline Yes & 194 & 31 \\
\hline No & 431 & 69 \\
\hline \multicolumn{3}{|l|}{ Life time use of chat } \\
\hline Yes & 186 & 29.8 \\
\hline No & 439 & 70.2 \\
\hline \multicolumn{3}{|l|}{ Life time use of tobacco } \\
\hline Yes & 78 & 12.5 \\
\hline No & 547 & 87.5 \\
\hline \multicolumn{3}{|l|}{ Current use of alcohol } \\
\hline Yes & 133 & 21.3 \\
\hline No & 492 & 78.7 \\
\hline \multicolumn{3}{|l|}{ Current use of chat } \\
\hline Yes & 115 & 18.4 \\
\hline No & 510 & 81.6 \\
\hline
\end{tabular}

(Continued)
Table 2 (Continued).

\begin{tabular}{|l|l|l|}
\hline Variables & Frequency & Percent (\%) \\
\hline Current use of tobacco & & \\
Yes & 21 & 3.4 \\
No & 604 & 96.6 \\
\hline
\end{tabular}

had not experienced the destruction of personal property ( $\mathrm{AOR}=1.58,95 \% \mathrm{CI} 1.04$ to 2.44 ). The odds of developing PTSD among participants who had witnessed or experienced the murder of family or friends were two times higher than those who had not witnessed or experienced this event (AOR=2.1, 95\% CI 1.08 to 4.08 ).

The odds of developing PTSD among those with depression were 2.6 times higher as compared to those without depression (AOR=2.6, 95\% CI 1.18 to 3.78). Participants who had been displaced more than once were 3.69 times more likely to develop PTSD than respondents who had never been displaced $(\mathrm{AOR}=3.69$, $95 \%$ CI 2.35 to 5.82). Respondents who had experienced 4 or more of the 16 trauma events included in the questionnaire were more likely to have PTSD (1.9 times more likely for 4-7 traumatic events, 2.9 times more likely for 8-11 traumatic events, and 4 times more likely for 12 or more traumatic events) than participants who had experienced 0-3 traumatic events of the 16 trauma events $(\mathrm{AOR}=1.9,95 \% \mathrm{CI} 1.1$ to 3.4$),(\mathrm{AOR}=2.9,95 \% \mathrm{CI} 2.3$ to 4.1$),(\mathrm{AOR}=4.1,95 \%$ CI 1.7 to 9.7$)$ (Table 4$)$.

\section{Discussion}

The findings from the current study revealed that the estimated prevalence of PTSD was $58.4 \%$ with $95 \%$ CI 55 to 61.9 ) among IDP. The prevalence of this study was in line with the study carried out in Sri Lanka (56\%). ${ }^{50}$

On the other hand, the finding of the current study was lower than study done in Medellin Colombia (88\%), ${ }^{33}$ and North Uganda (74\%). ${ }^{51}$ The discrepancy might be due to exposure to different trauma types, in which being abducted was the most frequently reported type in Colombia, ${ }^{47}$ and it might be more stressful than destruction of personal property, which was most frequently reported in the current study. ${ }^{51}$ Variation in study type and sampling technique might be another difference in the qualitative study and convenience sampling technique used in Colombia, ${ }^{33}$ and its result might be more biased 
Table 3 Description of Trauma-Related Factors Among Internally Displaced People in Southern Ethiopia 2019 ( $\mathrm{n}=625)$

\begin{tabular}{|c|c|c|c|c|}
\hline Traumatic Event Experienced by IDP & \multicolumn{3}{|c|}{ Frequency } & Percent (\%) \\
\hline \multicolumn{5}{|l|}{ Types of traumatic events } \\
\hline Destruction of personal property & \multicolumn{3}{|l|}{422} & 67.52 \\
\hline Lack of housing or shelter in the camp & \multicolumn{3}{|l|}{230} & 36.8 \\
\hline Lack of food or water in the camp & \multicolumn{3}{|l|}{382} & 61.12 \\
\hline Witnessing murder of family member/friend & \multicolumn{3}{|l|}{348} & 55.68 \\
\hline III health without medical care & \multicolumn{3}{|l|}{316} & 50.56 \\
\hline Forced isolation from other people & \multicolumn{3}{|l|}{342} & 54.72 \\
\hline Tortured or beaten & \multicolumn{3}{|l|}{292} & 46.72 \\
\hline Serious injury & \multicolumn{3}{|l|}{290} & 46.4 \\
\hline Witnessing murder of stranger & \multicolumn{3}{|l|}{250} & 40 \\
\hline Made to accept ideas against will & \multicolumn{3}{|l|}{198} & 31.68 \\
\hline Forced separation from family & \multicolumn{3}{|l|}{190} & 30.4 \\
\hline Unnatural death of family or friends & \multicolumn{3}{|l|}{178} & 28.48 \\
\hline Imprisonment against your will & \multicolumn{3}{|l|}{166} & 26.56 \\
\hline Being in a war fighting situation & \multicolumn{3}{|l|}{162} & 25.92 \\
\hline Being abducted or kidnapped & \multicolumn{3}{|l|}{114} & 18.24 \\
\hline Rape or sexual abuse & \multicolumn{3}{|l|}{48} & 7.68 \\
\hline \multicolumn{5}{|l|}{ Childhood physical abuse/neglected } \\
\hline Yes & \multicolumn{3}{|l|}{157} & 25.1 \\
\hline No & \multicolumn{3}{|l|}{468} & 74.9 \\
\hline Exposure to cumulative trauma events & Male & Female & Total & \\
\hline $0-3$ trauma events & 190 & 118 & 308 & 49.28 \\
\hline 4-7 trauma events & 25 & 33 & 58 & 9.28 \\
\hline $8-11$ trauma events & 108 & 111 & 219 & 35.04 \\
\hline $12-16$ trauma events & 5 & 35 & 40 & 6.4 \\
\hline Total & 328 & 297 & 625 & 100 \\
\hline
\end{tabular}

and subjective than probability sampling, which was used in current study. The difference in the instrument might be another reason for this variation, PTSD was assessed by using a culturally-validated 24-item PTSD-check list in Colombia, ${ }^{33}$ PCL-C for DSM-IV in Nigeria, but PCL-5 with LEC-5 and extended criteria A was used in the current study. ${ }^{49}$ It might be also due to a difference in sample size and study setting in which IDPs living in a camp and in the host community was included and a larger sample size was used in northern Uganda, ${ }^{51}$ but in this study participants living in the host community were excluded.

Contrarily, the estimated prevalence of the current study was higher than the studies carried out in Nigeria $(42 \%),{ }^{32}$ Darfur (54\%), ${ }^{36}$ Sri Lanka (2.3\%), ${ }^{29}$ Georgia $(23.3 \%),{ }^{52}$ Iraq $(20.8 \%),{ }^{53}$ Central Sudan $(12.3 \%),{ }^{31}$ and Sindh $(9 \%){ }^{54}$ The possible explanation for the observed differences could be the difference in tools, in which Nigeria and Iraq's studies used the Harvard trauma questionnaire (HTQ), ${ }^{32,52}$ structured interview using DSM-IV-
TR was used in Sindh, ${ }^{54}$ and the k-section of the Composite International Diagnostic Interview (CIDI) was used in Sri Lanka, ${ }^{29}$ but the current study used PCL-5 with LEC-5 and extended criteria A which was modified with a better internal consistent to measure PTSD. ${ }^{49}$ An other reason might be duration of displacement; the study in Sri Lanka was conducted after 20 years of forced displacement, ${ }^{29}$ after 10 years in Georgia, ${ }^{52}$ after 2 years in Nigeria, ${ }^{32}$ but the current study was conducted less than 2 years after forced displacement. ${ }^{2}$ Hence, the increased duration of displacement was more likely to reduce the magnitude due to recall bias. Variations in type of exposure to trauma, sampling techniques and socio-cultural factors might be another reason. ${ }^{29,36,53}$

Females were 2.4 times more likely to have PTSD compared to males. This may be because females have a higher risk of developing PTSD due to a lower threshold from exposure to psycho-trauma compared to males. ${ }^{33}$ It might be also due to a direct psychological consequence of rape or sexual abuse, the violent loss of partner, children and of 
Table 4 Bi-Variable and Multivariable Binary Logistic Regression Analysis Showing an Association Between Factors and Post-Traumatic Stress Disorder Among Internally Displaced People in Southern Ethiopia $2019(n=625)$

\begin{tabular}{|c|c|c|c|c|}
\hline \multirow[t]{2}{*}{ Explanatory Variables } & \multicolumn{2}{|c|}{ PTSD } & \multirow[t]{2}{*}{ COR $(95 \% \mathrm{CI})$} & \multirow[t]{2}{*}{ AOR (95\% Cl) } \\
\hline & Yes & No & & \\
\hline \multicolumn{5}{|l|}{ Sex } \\
\hline Female & 223 & 75 & $3.87(2.84,5.37)$ & $2.35(1.61,3.44)^{* * *}$ \\
\hline Male & 142 & 185 & 1 & 1 \\
\hline \multicolumn{5}{|l|}{ Co-morbid medical illness } \\
\hline Yes & 61 & 31 & $\mathrm{I} .47(0.95,2.25)$ & $1.26(0.76,2.08)$ \\
\hline No & 305 & 228 & 1 & 1 \\
\hline \multicolumn{5}{|l|}{ Frequency of displacement } \\
\hline >one time & 211 & 51 & $5.55(3.97,7.89)$ & $3.69(2.35,5.82)^{* *}$ \\
\hline Once & 155 & 208 & I & I \\
\hline \multicolumn{5}{|l|}{ Depression } \\
\hline Yes & 228 & 105 & $2.46(1.82,3.34)$ & $2.6(1.79,3.78)^{* * *}$ \\
\hline No & 137 & 155 & 1 & 1 \\
\hline \multicolumn{5}{|c|}{ Destruction of personal property } \\
\hline Yes & 266 & 158 & $1.67(1.26,2.37)$ & $1.58(1.04,2.44)^{*}$ \\
\hline No & 101 & 100 & 1 & 1 \\
\hline \multicolumn{5}{|l|}{ Lack of food and water } \\
\hline Yes & 246 & 136 & $\mathrm{I} .85(\mathrm{I} .37,2.5 \mathrm{I})$ & $1.17(0.13,1.37)$ \\
\hline No & 120 & 123 & I & 1 \\
\hline \multicolumn{5}{|l|}{ III without medical care } \\
\hline Yes & 202 & 114 & $1.59(1.18,2.14)$ & I.3I $(0.56,3.04)$ \\
\hline No & 163 & 146 & I & 1 \\
\hline \multicolumn{5}{|c|}{ Witnessing murder of family/friends } \\
\hline Yes & 231 & 117 & $2.08(I .54,2.8 I)$ & $2.1(1.08,4.08)^{* *}$ \\
\hline No & 135 & 142 & 1 & I \\
\hline \multicolumn{5}{|l|}{ Tortured or beaten } \\
\hline Yes & 189 & 104 & $1.61(1.20,2.18)$ & $1.52(0.23,1.79)$ \\
\hline No & 176 & 156 & 1 & 1 \\
\hline \multicolumn{5}{|l|}{ Cumulative trauma } \\
\hline $4-7$ & 39 & 21 & $2.3(1.32,3.99)$ & $1.9(1.1,3.4)^{* *}$ \\
\hline $8-11$ & 156 & 63 & $3.07(2.18,4.33)$ & $2.9(2,4.1)^{* * *}$ \\
\hline $12-16$ & 33 & 6 & $6.82(3.01,15.85)$ & $4.1(1.7,9.7)^{* * *}$ \\
\hline $0-3$ & 137 & 170 & 1 & 1 \\
\hline
\end{tabular}

Notes: ${ }^{*} \mathrm{p}<0.05$; ${ }^{*} \mathrm{p}<0.01$; ${ }^{* * *} \mathrm{p}<0.00 \mathrm{I}$; chi-square, 5; df, 8; HosmerLemeshow test, 0.69 .

Abbreviations: COR, crude odds ratio; AOR, adjusted odds ratio; $n$, sample size.

becoming single parent or widow. ${ }^{36,51}$ In fact the exposure to traumatic events had high impact among females when compared with males. ${ }^{36,42}$ Another reason could be that females tend to show a more emotional and ruminative response to stress. ${ }^{50,55}$ This could increase the risk of developing PTSD.

Another factor strongly associated with PTSD was depression; participants with depression were 2.6 times more likely to have PTSD when compared to respondents without depression. This could be because participants with depression are more likely to have suffered traumatic experiences than respondents without depression, ${ }^{55}$ which in turn increases the likelihood of PTSD development. PTSD was more common among depressed patients than those without depression. Having previous depression and another psychological disorders might be another reason for the increased risk of developing PTSD. ${ }^{32,50}$

Regarding frequency of displacement, participants who were displaced more than once were 3.7 times more likely 
to have PTSD than respondents who were only displaced once. This might be because respondents with repeated displacement were more likely to be exposed to trauma and violence than participants only displaced once, hence repeated exposure to displacement-related trauma might increase the risk of developing PTSD. ${ }^{56,57}$

In addition, the destruction of personal property was significantly associated with PTSD in this study. Those who had experienced this event were 1.58 times more likely to have PTSD than those who had not experienced it. This might be because participants feel that those type of losses will be difficult, if not impossible, to replace, resulting in increased psychological distress. ${ }^{32}$ Also, following traumatic events like destruction of personal property, acute stress is a typical response, if this problem persists it may increase the risk of developing PTSD. ${ }^{32}$

Participants who had witnessed or experienced the murder of family or friends were twice as likely to have PTSD than those who had not experienced this event. This could be because the effect of losing a loved one may resemble the experiences of other types trauma victims, including reminders of the event, negative intrusive thoughts like thoughts of revenge and it may have a significant impact on emotional well-being. ${ }^{32,58}$ Those who have witnessed the violent death of a family member might be at an increased risk of developing PTSD. ${ }^{59,60}$

Respondents who had experienced 4 or more of the 16 trauma events included in the questionnaire were more likely to have PTSD (1.9 times more likely for 4-7 traumatic events, 2.9 times more likely for 8-11 traumatic events and 4 times more likely for 12 or more traumatic events) than participants who had experienced 0-3 traumatic events of the 16 trauma events. This could be because when an individual is exposed to several traumatic events they have a greater negative influence on mental health than a single, discrete trauma. ${ }^{56,57,61}$ Greater exposure to multiple types of traumatic events may predict greater PTSD severity. ${ }^{51,62}$

\section{Conclusion}

A high rate of PTSD was found among internally displaced people. Depression, sex, frequency of displacement, witnessing the murder of family or friends, destruction of personal property, and cumulative trauma were found to be significant predictors of PTSD. Therefore, the Ministry of Health should do on-site screening and provide treatment for all IDPs suffering from for
PTSD and depression, establishing a referral system for mental health problems is recommended.

\section{Strength and Limitation of the Study}

The study has several strengths. First, it included important variables which were not included in previous studies. Second, it used updated standardized instrument for measuring PTSD. Third, validated and standardized tools were used to assess independent variables such as stressful life events and depression. Whereas, including participants or IDPs from a single place (zone), excluding IDPs hosted by relatives or friends or living in unregistered camps, mean there was an inability to consistently match the gender of interviewers and respondents to minimize under reporting of certain sensitive traumatic events, like rape or sexual abuse, and the majority of the study participants were adults; these this could be considered as some of the limitations of the study.

\section{Data Sharing Statement}

The data sets used and analyzed during the current study are available from the corresponding author on reasonable request.

\section{Acknowledgments}

Authors of this study would like to acknowledge the entire staff of the Gede'o zone Health Bureau and camp leaders for their cooperation. Our sincere gratitude goes to University of Gondar, College of Medicine and Health Sciences, Department of Psychiatry and Amanuel Mental Specialized Hospital's Research and Dissemination Office for funding the study. We also appreciate the study participants for their cooperation in providing the necessary information.

\section{Author Contributions}

All authors made a significant contribution to the work reported, whether that is in the conception, study design, execution, acquisition of data, analysis and interpretation, or in all these areas; took part in drafting, revising or critically reviewing the article; gave final approval of the version to be published; have agreed on the journal to which the article has been submitted; and agree to be accountable for all aspects of the work. 


\section{Disclosure}

The authors declare that they have no competing interests.

\section{References}

1. Shultz JM, Ceballos ÁMG, Espinel Z, Oliveros SR, Fonseca MF, Florez LJH. Internal displacement in Colombia: fifteen distinguishing features. Disaster Health. 2014;2(1):13-24. doi:10.4161/dish.27885

2. IDMC. 2018. Available from: www.internal-displacement.org/sites/ default/files/ .../2018-mid-year ethiopia.

3. Harlem GB. Mental health of refugees, internally displaced persons and other populations affected by conflict. Acta Psychiatr Scand. 2000;102:159.

4. Council NR, Grid I. Global report on internal displacement. 2016. Available from: http://www internal-displacement org/publications/ 2016/2016-global-report-on-internal-displacement-grid-2016.

5. Murthy RS, Lakshminarayana R. Mental health consequences of war: a brief review of research findings. World Psychiatry. 2006;5(1):25.

6. Sadock BJ, Sadock VA. Kaplan and Sadock's Synopsis of Psychiatry: Behavioral Sciences/Clinical Psychiatry. Lippincott Williams \& Wilkins; 2011.

7. Porter M, Haslam N. Predisplacement and postdisplacement factors associated with mental health of refugees and internally displaced persons: a meta-analysis. JAMA. 2005;294(5):602-612. doi:10.1001/ jama.294.5.602

8. Roberts B, Browne J. A systematic review of factors influencing the psychological health of conflict-affected populations in low-and middle-income countries. Glob Public Health. 2011;6(8):814-829. doi:10.1080/17441692.2010.511625

9. Chukwuorji JBC, Ifeagwazi CM, Eze JE. Event centrality influences posttraumatic stress disorder symptoms via core beliefs in internally displaced older adults. Aging Ment Health. 2019;23:113-121.

10. Eytan A, Gex-Fabry M, Toscani L, Deroo L, Loutan L, Bovier PA. Determinants of postconflict symptoms in Albanian Kosovars. $J$ Nerv Ment Dis. 2004;192(10):664-671. doi:10.1097/01.nmd.0000142029.96 703.57

11. De Jong JT, Komproe IH, Van Ommeren M. Common mental disorders in postconflict settings. Lancet. 2003;361(9375):2128-2130. doi:10.1016/S0140-6736(03)13692-6

12. Hapke U, Schumann A, Rumpf H-J, John U, Meyer C. Post-traumatic stress disorder. Eur Arch Psychiatry Clin Neurosci. 2006;256 (5):299-306. doi:10.1007/s00406-006-0654-6

13. Ö F, Rimmö PA, Åberg L, Fredrikson M. Trauma exposure and posttraumatic stress disorder in the general population. Acta Psychiatr Scand. 2005;111(4):291. doi:10.1111/j.1600-0447.2004.00463.x

14. Hobfoll SE, Canetti-Nisim D, Johnson RJ, Palmieri PA, Varley JD, Galea S. The association of exposure, risk, and resiliency factors with PTSD among Jews and Arabs exposed to repeated acts of terrorism in Israel. J Trauma Stress. 2008;21(1):9-21. doi:10.1002/ jts. 20307

15. Silove D, Steel Z, Bauman A, Chey T, McFarlane A. Trauma, PTSD and the longer-term mental health burden amongst Vietnamese refugees. Soc Psychiatry Psychiatr Epidemiol. 2007;42(6):467-476. doi:10.1007/s00127-007-0194-z

16. Fortes S, Lopes CS, Villano LA, Campos MR, Gonçalves DA, Mari J. Common mental disorders in Petrópolis-RJ: a challenge to integrate mental health into primary care strategies. Braz J Psychiatry. 2011;33 (2):150-156. doi:10.1590/S1516-44462011000200010

17. Steel Z, Chey T, Silove D, Marnane C, Bryant RA, Van Ommeren M. Association of torture and other potentially traumatic events with mental health outcomes among populations exposed to mass conflict and displacement: a systematic review and meta-analysis. JAMA. 2009;302(5):537-549. doi:10.1001/jama.20 09.1132
18. Morina N, Akhtar A, Barth J, Schnyder U. Psychiatric disorders in refugees and internally displaced persons after forced displacement: a systematic review. Front Psychiatry. 2018;9. doi:10.3389/fpsyt.20 18.00433

19. Pham PN, Weinstein HM, Longman T. Trauma and PTSD symptoms in Rwanda: implications for attitudes toward justice and reconciliation. JAMA. 2004;292(5):602-612. doi:10.1001/jama.2 92.5.602

20. Rieder H, Elbert T. Rwanda-lasting imprints of a genocide: trauma, mental health and psychosocial conditions in survivors, former prisoners and their children. Confl Health. 2013;7(1):6. doi:10.1186/ 1752-1505-7-6

21. Schaal S, Dusingizemungu J-P, Jacob N, Elbert T. Rates of trauma spectrum disorders and risks of posttraumatic stress disorder in a sample of orphaned and widowed genocide survivors. Eur $J$ Psychotraumatol. 2011;2(1):6343. doi:10.3402/ejpt.v2i0.6343

22. Karunakara UK, Neuner F, Schauer M, et al. Traumatic events and symptoms of post-traumatic stress disorder amongst Sudanese nationals, refugees and Ugandans in the West Nile. Afr Health Sci. 2004;4(2):83-93.

23. Onyut LP, Neuner F, Ertl V, Schauer E, Odenwald M, Elbert T. Trauma, poverty and mental health among Somali and Rwandese refugees living in an African refugee settlement-an epidemiological study. Confl Health. 2009;3(1):6. doi:10.1186/1752-1505-3-6

24. Ovuga E, Boardman J, Wasserman D. The prevalence of depression in two districts of Uganda. Soc Psychiatry Psychiatr Epidemiol. 2005;40(6):439-445. doi:10.1007/s00127-005-0915-0

25. Pfeiffer A, Elbert T. PTSD, depression and anxiety among former abductees in Northern Uganda. Confl Health. 2011;5(1):14. doi:10.1186/1752-1505-5-14

26. Roberts B, Ocaka KF, Browne J, Oyok T, Sondorp E. Factors associated with post-traumatic stress disorder and depression amongst internally displaced persons in northern Uganda. BMC Psychiatry. 2008;8(1):38. doi:10.1186/1471-244X-8-38

27. Vinck P, Pham PN, Stover E, Weinstein HM. Exposure to war crimes and implications for peace building in northern Uganda. JAMA. 2007;298(5):543-554. doi:10.1001/jama.298.5.543

28. Tamayo Martínez N, Rincón Rodríguez CJ, de Santacruz C, Bautista Bautista N, Collazos J, Gómez-Restrepo C. Problemas mentales, trastornos del afecto y de ansiedad en la población desplazada por la violencia en Colombia, resultados de la Encuesta Nacional de Salud Mental 2015. Revista Colombiana De Psiquiatría. 2016;45:113-118. doi:10.1016/j.rcp.2016.09.004

29. Husain F, Anderson M, Cardozo BL, et al. Prevalence of war-related mental health conditions and association with displacement status in postwar Jaffna District, Sri Lanka. JAMA. 2011;306(5):522-531. doi:10.1001/jama.2011.1052

30. Ceri V, Özlü-Erkilic Z, Özer Ü, Yalcin M, Popow C, AkkayaKalayci T. Psychiatric symptoms and disorders among Yazidi children and adolescents immediately after forced migration following ISIS attacks. neuropsychiatrie. 2016;30(3):145-150. doi:10.1007/ s40211-016-0195-9

31. Salah TT, Abdelrahman A, Lien L, Eide AH, Martinez P, Hauff E. The mental health of internally displaced persons: an epidemiological study of adults in two settlements in Central Sudan. Int $J$ Soc Psychiatry. 2013;59(8):782-788. doi:10.1177/0020764012456810

32. Sheikh TL, Mohammed A, Agunbiade S, Ike J, Ebiti WN, Adekeye O. Psycho-trauma, psychosocial adjustment, and symptomatic post-traumatic stress disorder among internally displaced persons in Kaduna, Northwestern Nigeria. Front Psychiatry. 2014;5:127. doi:10.3389/fpsyt.2014.00127

33. Richards A, Ospina-Duque J, Barrera-Valencia $\mathrm{M}$, et al. Posttraumatic stress disorder, anxiety and depression symptoms, and psychosocial treatment needs in Colombians internally displaced by armed conflict: a mixed-method evaluation. Psychol Trauma. 2011;3 (4):384. doi:10.1037/a0022257 
34. Akinyemi OO, Owoaje ET, Ige OK, Popoola OA. Comparative study of mental health and quality of life in long term refugees and host populations in Oru-Ijebu, Southwest Nigeria. BMC Res Notes. 2012;5:394. doi:10.1186/1756-0500-5-394

35. Priebe S, Matanov A, Janković Gavrilović J, McCrone P, Ljubotina D, Knežević G. Consequences of untreated posttraumatic stress disorder following war in former yugoslavia: morbidity, subjective quality of life, and care costs [Internet]. Croat Med J. 2009;50 (5):465-475. doi: $10.3325 / \mathrm{cmj} .2009 .50 .465$

36. Keane TM, Marshall AD, Taft CT. Posttraumatic stress disorder: etiology, epidemiology, and treatment outcome. Annu Rev Clin Psychol. 2006;2 (1):161-197. doi:10.1146/annurev.clinpsy.2.022305.095305

37. Essizoglu A, Keser I. Post-traumatic stress disorder in internally displaced people subjected to displacement by armed forces. J Trauma Stress Disor Treat. 2014;3(2):2-6.

38. Ergun D, Çakici M, Çakici E. Comparing psychological responses of internally displaced and non-displaced Turkish Cypriots. Torture. 2008;18(1):20-28.

39. Owoaje ET, Uchendu OC, Ajayi TO, Cadmus EO. A review of the health problems of the internally displaced persons in Africa. Nigerian Postgraduate Medical Journal. 2016;23(4):161. doi:10.4103/1117-1936.196242

40. Mugisha J, Muyinda H, Wandiembe P, Kinyanda E. Prevalence and factors associated with posttraumatic stress disorder seven years after the conflict in three districts in northern Uganda (The Wayo-Nero Study). BMC Psychiatry. 2015;15(1):170. doi:10.1186/s12888-0150551-5

41. Roberts B, Damundu EY, Lomoro O, Sondorp E. Post-conflict mental health needs: a cross-sectional survey of trauma, depression and associated factors in Juba, Southern Sudan. BMC Psychiatry. 2009;9:7. doi:10.1186/1471-244X-9-7

42. Getnet B, Medhin G, Alem A. Symptoms of post-traumatic stress disorder and depression among Eritrean refugees in Ethiopia: identifying direct, meditating and moderating predictors from path analysis. BMJ Open. 2019;9(1):e021142. doi:10.1136/bmjopen2017-021142

43. Weathers FW, Litz BT, Keane TM, Palmieri PA, Marx BP, Schnurr PP. The PTSD Checklist for DSM-5(PCL-5). National center for PTSD. 2013.

44. Ibrahim H, Ertl V, Catani C, Ismail AA, Neuner F. The validity of posttraumatic stress disorder checklist for DSM-5 (PCL-5) as screening instrument with Kurdish and Arab displaced populations living in the Kurdistan region of Iraq. BMC Psychiatry. 2018;18(1):259. doi:10.1186/s12888-018-1839-z

45. Verhey R, Chibanda D, Gibson L, Brakarsh J, Seedat S. Validation of the posttraumatic stress disorder checklist-5 (PCL-5) in a primary care population with high HIV prevalence in Zimbabwe. BMC Psychiatry. 2018;18(1):109. doi:10.1186/s12888-018-1688-9

46. Mollica R, Massagli L, Silove D. Measuring Trauma, Measuring Torture. Cambridge, MA: Harvard University; 2004.

47. Kaaya SF, Fawzi MS, Mbwambo J, Lee B, Msamanga GI, Fawzi W. Validity of the Hopkins symptom checklist-25 amongst HIV-positive pregnant women in Tanzania. Acta Psychiatr Scand. 2002;106 (1):9-19. doi:10.1034/j.1600-0447.2002.01205.x

Neuropsychiatric Disease and Treatment

\section{Publish your work in this journal}

Neuropsychiatric Disease and Treatment is an international, peerreviewed journal of clinical therapeutics and pharmacology focusing on concise rapid reporting of clinical or pre-clinical studies on a range of neuropsychiatric and neurological disorders. This journal is indexed on PubMed Central, the 'PsycINFO' database and CAS, and
48. Abiola T, Udofia O, Zakari M. Psychometric properties of the 3-item oslo social support scale among clinical students of Bayero University Kano, Nigeria. Malaysian J Psychiatry. 2013;22:32-41.

49. Weathers F, Blake D, Schnurr P, Kaloupek D, Marx B, Keane T. The life events checklist for DSM-5 (LEC-5). Instrument available from the National Center for PTSD at www ptsd va gov. 2013.

50. Ranasinghe PD, Levy BR. Prevalence of and sex disparities in posttraumatic stress disorder in an internally displaced Sri Lankan population 6 months after the 2004 Tsunami. Disaster Med Public Health Prep. 2007;1(1):34-41. doi:10.1097/DMP.0b013e318068fbb7

51. Roberts B, Ocaka KF, Browne J, Oyok T, Sondorp E. Factors associated with the health status of internally displaced persons in northern Uganda. J Epidemiol Community Health. 2009;63(3):227-232. doi:10.1136/jech.2008.076356

52. Makhashvili N, Chikovani I, McKee M, Bisson J, Patel V, Roberts B. Mental disorders and their association with disability among internally displaced persons and returnees in Georgia. J Trauma Stress. 2014;27(5):509-518. doi:10.1002/jts.21949

53. AlShawi A. Prevalence of posttraumatic stress disorders among sample of internally displaced persons in Iraq, a preliminary study. J Community Med Health Educ. 2018;8(599):2161-0711.1000599. doi:10.4172/2161-0711.1000599

54. Residing DPI. Psychological effects among internally.

55. Shevlin M, Hyland P, Vallières F, et al. A comparison of DSM-5 and ICD-11 PTSD prevalence, comorbidity and disability: an analysis of the Ukrainian internally displaced person's mental health survey. Acta Psychiatr Scand. 2018;137(2):138-147. doi:10.1111/acps.12840

56. Roberts B, Makhashvili N, Javakhishvili J, et al. Mental health care utilisation among internally displaced persons in Ukraine: results from a nation-wide survey. Epidemiol Psychiatr Sci. 2019;28: $100-111$.

57. Hamid AA, Musa SA. Mental health problems among internally displaced persons in Darfur. Int $J$ Psychol. 2010;45(4):278-285. doi:10.1080/00207591003692620

58. Elhabiby MM, Radwan DN, Okasha TA, El-Desouky ED. Psychiatric disorders among a sample of internally displaced persons in South Darfur. Int J Soc Psychiatry. 2015;61(4):358-362. doi:10.1177/ 0020764014547061

59. De Jong JT, Komproe IH, Van Ommeren M, et al. Lifetime events and posttraumatic stress disorder in 4 postconflict settings. JAMA. 2001;286(5):555-562. doi:10.1001/jama.286.5.555

60. Martskvishvili K. The relationship between emotional intelligance, coping and post traumatic stress disorder. 2010.

61. Thapa SB, Hauff E. Psychological distress among displaced persons during an armed conflict in Nepal. Soc Psychiatry Psychiatr Epidemiol. 2005;40(8):672-679. doi:10.1007/s00127-005-0943-9

62. Bogic M, Ajdukovic D, Bremner S, et al. Factors associated with mental disorders inlong-settled war refugees: refugees from theformer Yugoslavia in Germany, Italy and the UK. BJP. 2012;200: 216-223. doi:10.1192/bjp.bp.110.084764 tely online and includes a very quick and fair peer-review system, which is all easy to use. Visit http://www.dovepress.com/testimonials.php to read real quotes from published authors.

\section{Dovepress}

